\title{
Serological Evidence for Schmallenberg Virus Infection in Sheep of Portugal, 2014
}

\author{
Fernando Esteves, ${ }^{1, *}$ João R. Mesquita, ${ }^{1-3,{ }^{*}}$ Helena Vala, ${ }^{1,3}$ Joana Abreu-Silva, \\ Wim H.M. van der Poel, and Maria S.J. Nascimento ${ }^{2,4}$
}

\begin{abstract}
Between November and December of 2014, a serosurvey was set up to evaluate the presence of Schmallenberg virus (SBV) antibodies in sheep of Portugal. Sera $(n=1068)$ were tested using an indirect enzyme linked immunosorbent assay (ID Screen ${ }^{\circledR}$ Schmallenberg virus indirect, IDvet Innovative Diagnostics, Montpellier, France). The estimated occurrence of immunogobulin $\mathrm{G}(\mathrm{IgG})$ antibodies against SBV in sheep of Portugal was $12.8 \%$ (95\% confidence interval 11.0-15.0\%). This is the first study reporting the presence of SBV antibodies in sheep of Portugal.
\end{abstract}

Key Words: Seroprevalence—Schmallenberg virus—Sheep—Arbovirus—ELISA.

\section{Introduction}

B Y THE END OF THE SUMMER season of 2011, a sudden illness affecting dairy herds was reported in The Netherlands (Muskens et al. 2012). This disease, characterized by a steep decrease in milk production, watery diarrhea, and occasional fever, was later found to be caused by a new arbovirus, Schmallenberg virus (SBV). SBV belongs to the Simbu serogroup in the family Bunyaviridae, genus Orthobunyavirus and consists of a negative-stranded tripartite RNA genome of orthobunyaviruses comprised of a small (S), a medium (M) and a large (L) segment (Hoffmann et al. 2012). Culicoides spp. biting midges were found to be involved in virus transmission (Rasmussen et al. 2012). Moreover, high SBV RNA levels and the absence of ruminant $\beta$-actin mRNA in Culicoides obsoletus group midges strongly suggest that SBV replicates in these midges (Rasmussen et al. 2012). In nonimmune pregnant ruminants, SBV was able to cross the placenta and infect the fetus, causing malformations at the cerebrospinal and musculoskeletal levels. These are typically observed around term, several months after the infection event, and summarized as the arthrogryposis-hydranencephalysyndrome (Rasmussen et al. 2012).
Since the emergence of SBV in 2011, the virus has spread throughout Europe, with reports documenting infection in Belgium (December, 2011), the United Kingdom and France (January, 2012), and Luxembourg and Italy (February, 2012) (Doceul et al. 2013). Spain reported the disease in a newborn lamb in March of 2012 and in the municipality of Hinojosa del Duque (ProMed-mail 2012). Despite proximity to the Portuguese border, to the best of our knowledge there are no reports of SBV infection in Portugal. However, the Spanish case has alerted us to the possibility of SBV introduction in Portugal. Hence, a serosurvey was set up to estimate the presence of immunoglobulin $\mathrm{G}$ (IgG) antibodies against SBV in sheep in Portugal that could allow us to infer the presence of SBV infection in the Portuguese territory.

\section{Materials and Methods}

\section{Sample size calculation}

The sample size to estimate the occurrence of IgG antiSBV antibodies in sheep in Portugal was calculated according to previously described methods (Abramson et al. 2011). It was assumed an IgG antibody seroprevalence against SBV of $50 \%$ (yielding the highest possible sample size), a confidence

\footnotetext{
${ }^{1}$ Escola Superior Agrária de Viseu, Instituto Politécnico de Viseu, Viseu, Portugal.

${ }^{2} \mathrm{CIBIO} / \mathrm{UP}$, Centro de Investigação em Biodiversidade e Recursos Genéticos/Universidade do Porto, Campus Agrário de Vairão, Vairão, Portugal.

${ }^{3}$ Centro de Estudos em Educação, Tecnologias e Saúde (CI\&DETS), Instituto Politécnico de Viseu, Viseu, Portugal.

${ }_{5}^{4}$ Laboratório de Microbiologia, Faculdade de Farmácia da Universidade do Porto, Porto, Portugal.

${ }^{5}$ Central Veterinary Institute of Wageningen University and Research Centre, Lelystad, the Netherlands.

*These authors contributed equally to this work.
} 
in the estimate of $95 \%$, a maximum allowable error in the prevalence of $3 \%$, and a population size of 1,852,940 sheep (Instituto Financiamento da Agricultura e Pescas [IFAP] 2013). These conditions yielded a calculated sample size of 1068 sheep. However, because sheep housed in Portugal are distributed heterogeneously according to region, a stratified random sampling design was set up with the five regions of continental Portugal (north, center, Lisboa and Vale do Tejo, Alentejo, and Algarve) as a stratification level, according to the Nomenclature of Units for Territorial Statistics (NUTS) II. On the basis of the census data of Animal Statistics Portugal of the total population size of $\approx 1.9$ million head of sheep in Portugal, 278,724 sheep are located in the north $(15 \%), 416,355$ in the center $(22.5 \%), 32,638$ in Lisboa and Vale do Tejo (1.8\%), 1,083,449 in Alentejo (58.5\%), and 41,774 in Algarve (2.2\%) (IFAP 2013). Because no herd level statistics were available, to represent better the five regions of Continental Portugal that were sampled, we collected blood from four farms spread within each region (at the north, south, east, and west).

\section{Enzyme-linked immunosorbent assay screening}

Blood was collected from female sheep with 6 months to 10 years of age (average age of 5 years) $(n=1068)$. All sera were from sheep born in Portugal. Samples were taken from animals randomly selected upon the moment of the official brucellosis control. Collection took place between November and December of 2014 from the five regions of Portugal: 161 samples from the north, 240 from the center, 19 from Lisboa and Vale do Tejo, 624 from Alentejo, and 24 from Algarve. Sera were tested for the presence of IgG anti-SBV antibodies using an enzyme linked immunosorbent assay (ID Screen ${ }^{\circledR}$ Schmallenberg virus indirect, IDvet Innovative Diagnostics, Montpellier, France) (sensitivity of $97.7 \%$ and specificity of $99.7 \%$ ), with a sampleto-positive control serum value of $60 \%$ assumed as cutoff (according to the manufacturers' instructions).

\section{Results and Discussion}

The seroprevalence of IgG anti-SBV antibodies in female sheep older than 6 months old of Portugal, NovemberDecember of 2014 (137 positive, $n=1067)$ was $12.8 \%(95 \%$ confidence interval [CI] 11.0-15.0\%). The seroprevalence found in Portugal is low when compared with the seroprevalence observed among sheep in Belgium (84.3\%), a country that underwent a recent emergence of SBV (Méroc et al. 2014).

The occurrence of IgG anti-SBV antibodies in sheep in the north of Portugal $(n=13 ; 8.1 \%, 95 \%$ CI 4.8-13.3\%) was lower than the estimated occurrence of IgG anti-SBV antibodies in the center $(n=34 ; 14.2 \%, 95 \%$ CI 10.3-19.2\%), Lisboa and Vale do Tejo $(n=6 ; 31.6 \%, 95 \%$ CI $15.4-54 \%)$, Alentejo $(n=79 ; 12.7 \%, 95 \%$ CI 10.3-15.5\%), and Algarve $(n=5 ; 20.8 \%, 95 \%$ CI 9.2-40.5\%) (Fig. 1). The occurrence of IgG anti-SBV antibodies in sheep is higher in the central/ southern strip of Portugal than in the remaining parts of the country. This finding could indicate that SBV was first introduced into the central/southern part of Portugal. Curiously, this is in the same latitude where the first SBV case in Spain occurred (ProMED-mail 2012). Interestingly, previous studies on the spatial distribution of Culicoides spp. in Portugal have shown that these SBV vectors are mainly con-

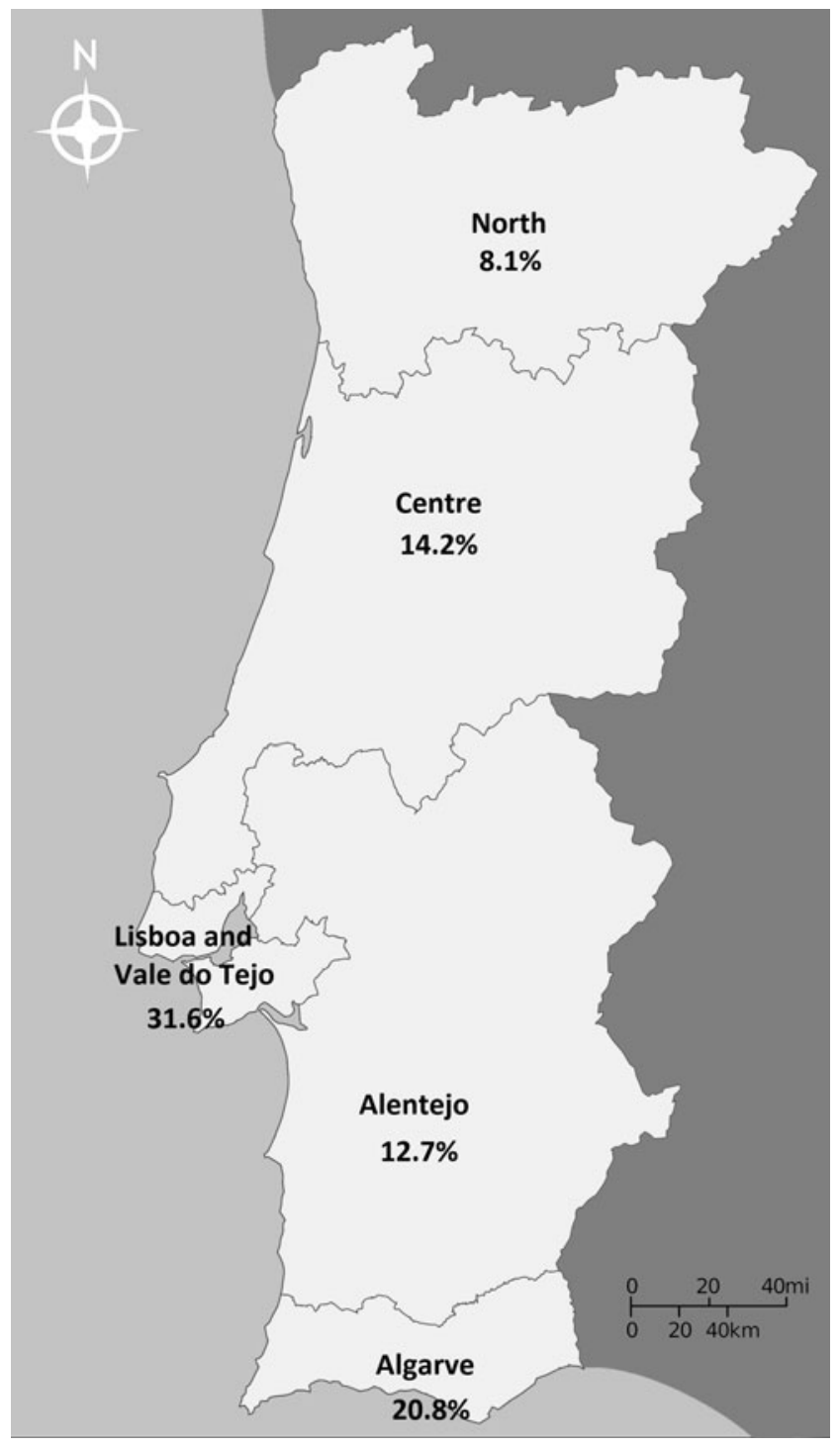

FIG. 1. Percentages of immunoglobulin $\mathrm{G}$ (IgG) antiSchmallenberg virus (SBV)- positive sheep in the five regions of continental Portugal, according to the stratification level of Nomenclature of Territorial Units for Statistics (NUTS II).

formed to the central/southern regions of the country (Capela et al. 2003), supporting our findings of higher SBV seropositivity in the south of Portugal.

Our data are inclusively in correspondence with the spatial distribution of Portuguese outbreaks of other Culicoides spp.borne diseases, such as African horse sickness and bluetongue, which are more prevalent in the southern versus the northern regions (Capela et al. 2003). Caution should be taken when analyzing these results because only four flocks were sampled per region (due to the lack of statistics at the herd level), leading to a cluster sampling approach that might introduce bias. Whether SBV was very recently introduced in Portugal still needs to be confirmed, ideally by seroprevalence studies on archived ruminant sera from 2011 to 2013.

A previous report suggested that the windborne transmission of Culicoides spp. midges from Morocco to the Iberian Peninsula through the Mediterranean Sea by southeast winds could have been responsible for bluetongue introduction 
(Capela et al. 2003). Studies have shown that the prevailing winds are generally from the northwest and west in summer and from the east and southeast in winter (Sousa et al. 2007). If windborne transport of Culicoides spp. takes place southbound, most likely in the summer, the potential introduction of SBV to North African countries can occur. Emergence of SBV in North Africa is of particular concern because this region is heavily dependent on SBV-susceptible animals (sheep, cattle, and goats) due to cultural and religious reasons.

In conclusion, this is the first study reporting the presence of SBV antibodies in the sheep of Portugal. However, to provide direct evidence of SBV infection in Portugal, further studies on the genetic characterization of SBV in both the vector and sheep are essential.

\section{Acknowledgments}

The authors would like to acknowledge IDvet Innovative Diagnostics and AMBIFOOD for providing financial support in the acquisition of the enzyme-linked immunosorbent assay (ELISA) kits. We would also like to thank the farmers who gave access to their animals. This work was supported by European Union Funds (QREN/FEDER) under the project Ovislab ICT-2013-05-004-5314 ID-64757.

\section{Author Disclosure Statement}

No competing financial interests exist.

\section{References}

Abramson JH. WINPEPI updated: Computer programs for epidemiologists, and their teaching potential. Epidemiol Perspect Innov 2011; 8:1.

Capela R, Purse BV, Pena I, Wittman EJ, et al. Spatial distribution of Culicoides species in Portugal in relation to the transmission of African horse sickness and bluetongue viruses. Med Vet Entomol 2003; 17:165-177.
Doceul V, Lara E, Sailleau C, Belbis G, et al. Epidemiology, molecular virology and diagnostics of Schmallenberg virus, an emerging orthobunyavirus in Europe. Vet Res 2013; 44:31.

Hoffmann B, Scheuch M, Höper D, Jungblut R, et al. Novel Orthobunyavirus in cattle, Europe, 2011. Emerg Infect Dis 2012; 18:469-472.

Instituto Financiamento da Agricultura e Pescas (IFAP). 2013. Available at www.ifap.min-agricultura.pt/portal/page/portal/ F73E9028F8EB5096E043C0A8C8C55096

Méroc E, De Regge N, Riocreux F, Caij AB, et al. Distribution of Schmallenberg virus and seroprevalence in Belgian sheep and goats. Transbound Emerg Dis 2014; 61:425-431.

Muskens J, Smolenaars AJG, van der Poel WHM, et al. Diarrhea and loss of production on Dutch dairy farms caused by the Schmallenburg virus. Tijdschr Diergeneeskd 2012; 137: 112-115.

ProMED-mail. Schmallenberg virus-Europe (28). Spain (Andalucia): OIE. 2012. Available at www.promedmail.org/direct .php?id=20120314.1070877

Rasmussen LD, Kristensen B, Kirkeby C, Rasmussen TB, et al. Culicoids as vectors of Schmallenberg virus. Emerg Infect Dis 2012; 18:1204-1206.

Sousa SIV, Martins FG, Alvim-Ferraz MCM, Pereira MC, et al. Multiple linear regression and artificial neural networks based on principal components to predict ozone concentrations. Environ Model Softw 2007; 22:97-103.

Address correspondence to: João Rodrigo Mesquita Escola Superior Agrária de Viseu Quinta da Alagoa Estrada de Nelas Ranhados, 3500-606 Viseu Portugal

E-mail: jmesquita@esav.ipv.pt 